SB 273

.T62

Copy 1

BACCO CULTURE

ADAPTHD

TO THE

NORTHERN SEOTION

OF TIE

UINITED STATHS,

AND THE

MOST IMPRUVED METHOD

?

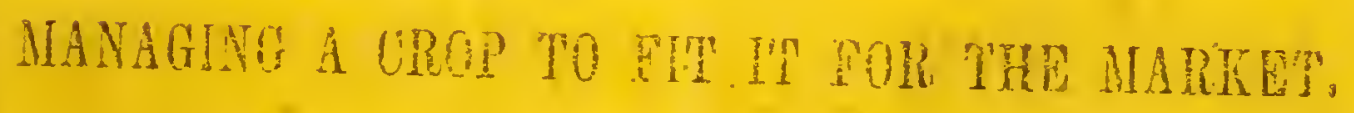

SECOND WDITIOTH-REVISTID.

\title{
5
}

PUIBLISHED ISY

CIIA. W. CRNEII,

SIRACUSE, N. Y.

1864. 
Ent Aful $30^{\text {th }} / 864$

Depos.dume $6 \frac{1}{"} / 864$ 


\title{
TOBACCO CULTURE
} ADAPTED

TO THE

\section{NORTHERN SECTION}

\author{
OF THE
}

\section{UNITED STATHS,}

AND THE

\section{MOST IMPROVED METHOD}

MANAGING A CROP TO FIT IT FOR THE MARKET.

SECOND EDITION-REVISED.

\section{PUBLISHED BY}

CHAS. W. CORNELL,

SYRACUSE, N. Y. 1864. 
Entered according to Act of Congress, in the year of 1864, by CHARLES $W$. CORNELL,

In the Clerk's Office, of the United States District Court for the Northern District of New York.

26041

Truair, Smith \& Miles,

\begin{tabular}{c} 
Printers and Stereos Y Pens, \\
Syracuse, N. Y. \\
\hline
\end{tabular}

$S B 27^{3}$
$T 62$ 


\section{P R E F A C .}

The author of the following pages was induced to write a Treatise on Growing Tobacco, some ten years since. At that time there had not been a publication of any description on the subject, and there was felt to be a want of some guide and instruction on the subject by those who desired to engage in its culture.

The first edition was long since exhausted. Increasing attention to the growing of Tobacco, and the demand for a manual on the subject, the author thinks a sufficient warrant to publish a new edition, and he trusts that the book will be found to contain all that is necessary for the successful cultivation of and curing of the crop. Other methods of handling a crop in the Tobacco house, and in various stages of the crop, are practiced in some portions of the Western States; but none of these plans are considered better than the one we have adopted. We give only one plan, as many plans presented to a beginner only confuse him and leave the mind in doubt as to the best one to follow. 



\section{TOBACCO CULTURE.}

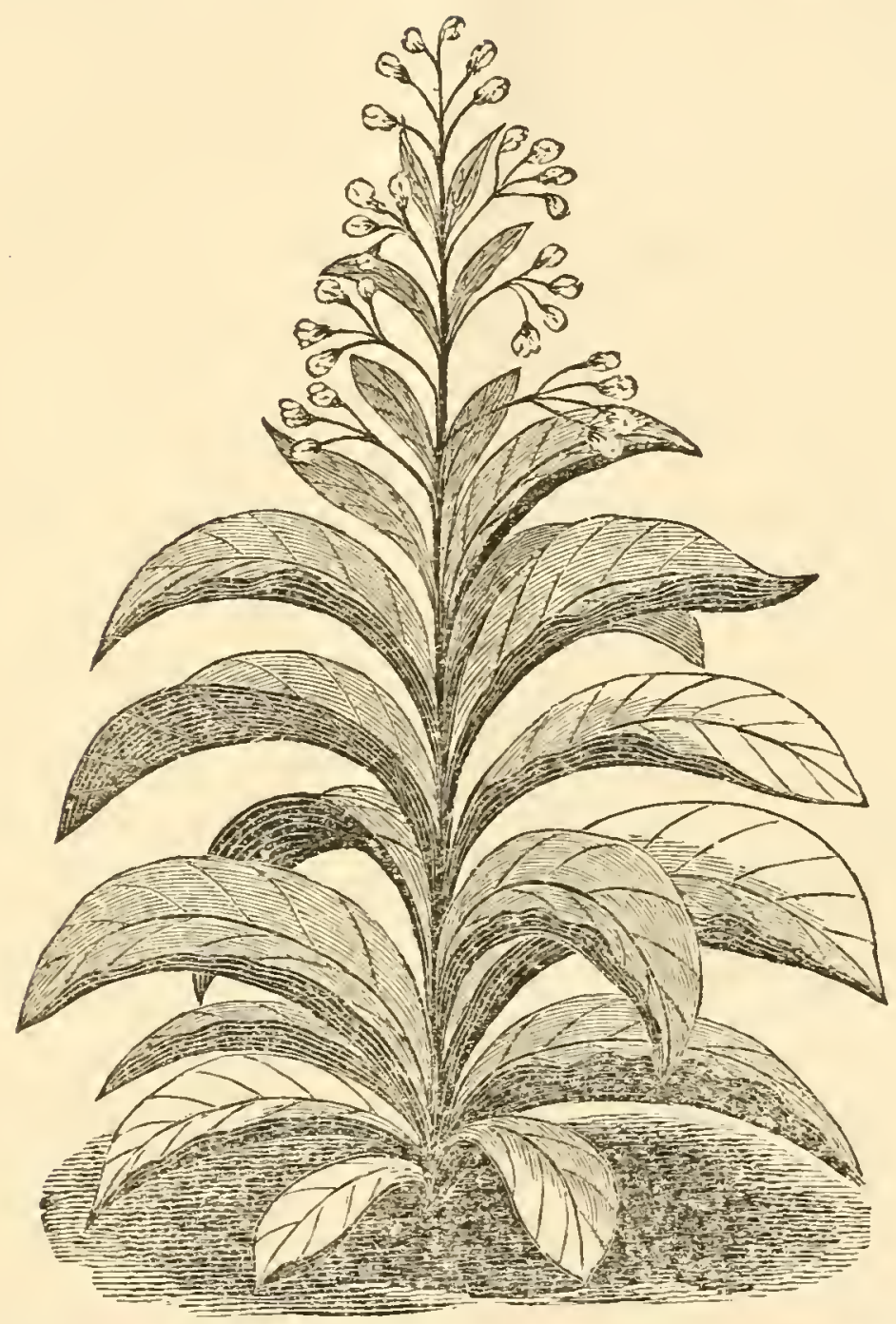

Fig. 1. Tle Tobacco Plant in full Blossom.

The Tobacco crop of the Northern States has, of late years, become of considerable consequence, as an article of commerce; incraasing, from year to year, in quantity as well as in improved quality, and the time bas come when the Tobacco of the North, is to be a staple commodity here, as it already is, in some of the Southern States. It is, therefore, very important to the Farmers of the North, that they 
should understand the growing, and managing of this crop, at as early a day as possible; and it is advisable that whatever is done, should be done well, for much depends on the first impression that shall be entertained with regard to the quality of any new article. Heretofore it has been supposed that Tobacco could only be raised in the Southern States, at least, in such quantity as to warrant its cultivation as a regular business of the Farmer; but experience has proved, that the Northern Tobacco, for the purposes for which it is used, is superior to most of the Tobacco of the South. It can hardly be said, however, that the Tobacco of the North, and that of the South, come in competition with each other; both have their particular uses, and are both wanted in the market. It only devolves on the Northern Farmer to understand well the business, and produce a good article; if he does this, he may be assured of a full recompense for his labor.

The best possible essay on the growth of any product of the soil will be more intelligible, and convey a more perfect knowledge of the subject, when to theory, is added experience. The want of a practical treatise on the suoject of growing Tobacco, has compelled the growers to trust to uncertain, and often incorrect information, obtained from those equally inexperienced with themselves; consequently many mistakes have been made, which might have been avoided, had only the ger'l rules to be observed been well understood; and it is the want of these general rules in any written form, that has induced the writer, to give the best experience of Tobacco growers in the present form; with the hope that it may be 
useful. It was thought best to give the whole process, as nearly as could be done, from the sowing of the seed to fitting the crop for market; in so doing, many apparently very simple statements have been made, in order to make the book more complete; and it is also, very possible, that some facts of more importance may not have been as clearly stated as they should have been, or, perhaps, entirely overlooked. The reader must bear in mind that there is great difficulty in giving the minute detail of any business in writing, and there is perhaps no product of the soil that requires more experience, and is subject to more casualties, than a crop of Tobacco; hence it is advisable to commence the growing of it, on a small scale, to be increased with further knowledge.

In order to understand the raising and curing of tobacco, in any part of the country, the particu'ar object or use, for which the tobacco is wanted, should be known and understood; this being the case, an in telligent purpose wiil be manifest frow the begining to the end, without which, no favorable result can be looked for.

Circumstances growing out of a difference in soils and climate, and many incidents which may occur, render it very difficult to give all the information that may be wanted; general rules and the best practice, is all that can be given to assist those who may desire to engage in the business of raising tobacco.

The tobacco grown in Connecticut, New York, Pennsylvania, and Ohio, is used for making cigars; but chiefly for the outside, or wrappers for cigars made of imported tobacco; for this purpose, only the 
best leaves are used, and it is in order to obtain these best leaves, (the "wrappers,") that this tobacco is cultivated; the poorer leaves, the small, torn, and badly colored leaves of the crop are called fillers, and are used for the inside or filling of cigars of a cheaper quality; but they are more generally used for "cutting" into smoking tobacco, to be smoked in pipes. This poor grade of tobacco, is only an incident acci. dental to getting the finer quality or wrappers, and is not an ohject sought in raising the crop; much of this tobacco of both qualities is exported to Europe, where it is manufactured, and not a little of it is returned to this country in the shape of cigars. The grower should have in view the particular uses of the crop, which will assist him and lead him to inquire as to the best method to be pursued, to produce the article wanted.

What is wanted, in what is called the "Seed Leaf" tobacco, (from having been produced by planting the Havana seed in Northern States, is a good sized, broad leaf, with small veins, and as thin, soft and silky, as can be produced; how to get this size, texture, and the color desired, the writer has endeavored to explain in the following pages.

\section{LAND, TO BE USED.}

The character, or kind of land to be used, for a fine crop of Seed Leaf Tobacco, should be first considered. An analysis of soils is not intended here, nor is it necessary for the present purpose; a few suggestions only will be sufficient to guide the grower. Ex. 
perience has determined that the uplands, the good corn and wheat lands, produce the finest quality of tobacco. Interval, or low lands will produce as large a crop, but the tobacco will be found less desirable, as it is liable to grow a thick, coarse leaf, and sometimes it will not burn freely, or burn to white ashes, and some drained swamp lands will grow tobacco that will not burn at all. Therefore it is only necessary in selecting the land, to choose a good, free, upland soil, which if well manured and well cultivated, will not be likely to disappoint the grower. All lands liable to be overflowed, by heavy showers, or long continued rains, and all hollows subject to standing waters, should be aroided; as tobacco will not grow in water, but will be destroyed by water standing about its roots for a few hours. The better thelands, the better drained, and manured, the more tobacco, and of finer quality, can be raised to the acre. One ton of tobacco to the acre, can be raised where all the circumstances are favorable.

\section{SEED, AND THE WANNER OF SOWING.}

In the selection of seed, care should be taken to procire none but the most approved variety. The seed of the broad leaf tobacco is the kind generally used for growing the fine wrapper; there are narrow leafed varieties, that grow equally well with the broad, but the narrow leaf does not answer so good a purpose, and is not a saleable article. Seed should be changed often; for if the seed grown on the same land from year to Jear, from the same original stock, 
is used for a number of year's, the quality of the tobacco will deteriorate. If a good article of seed is procured, seed can be raised and saved from this that will keep, and be fit for use, for a number of ycars. To raise the seed, allow a few of the earliest and best plants in the field to grow to their full size. One plant will produce seed enough for two acres. Break off the late buds from the seed plants so that none but the earliest and best will be saved. After harvesting is over, and the sced buds have become browned, cut up the stalk and hang it up to dry, by the top of the stalk, as the seeds will drop out if hung up by the butt. When thorunghly dry, take the seeds from the bud, and put them away in a dry place. To re. new the seed, sow the seed of Harana tobacco, and save the seed of the third year, wher it will be fit for use, and will hold good for several years from the renewal.

\section{TIME AND MANNER OF SOWING.}

Tobacco seed may be sown as early in the spring, as the frost is out of the ground, and the land dry enough to work. The spot selected for sowing the seed, should be rich, and well manured with old or rotten barn-yard manure; or with what is considered better, with hog manure, as this is the strongest, and most free from the seeds of weels and grass. It is a good plan to prepare the bed for plants in the autumn; cover well with hog manne and let it remain till spring, then rake it over and sow the seed. In the selection of a spot, choose a southerly aspect; beds 
of seven or eight feet in width, are prferable to wider ones, in order that the weeding may be done with more ease. Round off the beds a little, to prevent standing water after heavy rains; having well spaded the ground, and turned in, and mixed the manure, rake thoroughly so as to pulverize well the soil, then roll the beds with a garden roller, or in its place, take a plank as long as the width of the bed and press it thoroughly with the feet, by standing upon it. Mix the seed with sand or Indian meal, in quantity of a table spoon full of seed to a quart of sand or meal; the object of this, is, to be able to sow more evenly; the seed being so small, it is difficnlt, without some mixture of this kind, to sow little enongh upon a given spot. A table spoonful of seed will be sufficient for a bed of eight feet by twenty ; and produce plants enough for one or two acres of tobacco, according to the success in obtaining good and thrify plants; it is always prudent to sow donble the quantity of seed, and have double the quantity of plants actually wanted, in order to make a selection of the first grown and most flourishing. Those plants are the best that grow separately, or not too many in a bunch. Where the plants are very thick, they should be thinned out in weeding, as the cluster plants are weak and tender, and have fewer, and more delicate roots to sustain them when transplanted; and shonld not be used. Burning the beds for plants, is practiced in many places; this is done for the purpose of destroying the seeds of weeds, and for enriching the ground with the ashes. After the bed is well prepared and raked off, it is covered with small brushwood and straw, and set on tire; after the burning, it is again raked aud roll- 
ed, as before stated, and the seed sown. The seed should be sown broad-cast, and not covered, but rolled in with a roller, or pressed with a plank.

\section{WEEDING THE PIAITTS.}

It is very desirable that the spot selected for the bed of plants, should be as free from all kinds of foul secds as possible, as the weeding is of no small moment; and should be commenced as soon as the plants are up and are distingnishable from the weeds; in order to weed advantageonsly, have a plank bench as long as the width of the bed; the legs to stand in the paths, and of suticient length to raise the bench a few inches above the plants; sit or lie on these benches in weeding; put the weeds in a basket and lemore them from the beds. In weeding, it is best, if the plants come up too thickly, to thin out the chusters, by removing the sinallost and weakest plants; weed thoroughly, as plints cannot be raiced amoug grass and weeds; and continue the weeding till the time of transplantiug.

\section{TRANTSI AIVTING.}

Transplanting on taking up the plants for setting, is done with any sharp instrument that will enter the ground easily. A common table fork, or a piece of hard wood whittled as a spade, will answer. Care should be used in taking up the plants, that the roots are not broken off ; they should all be allowed to remain on the plants; the plants preferred for setting, 


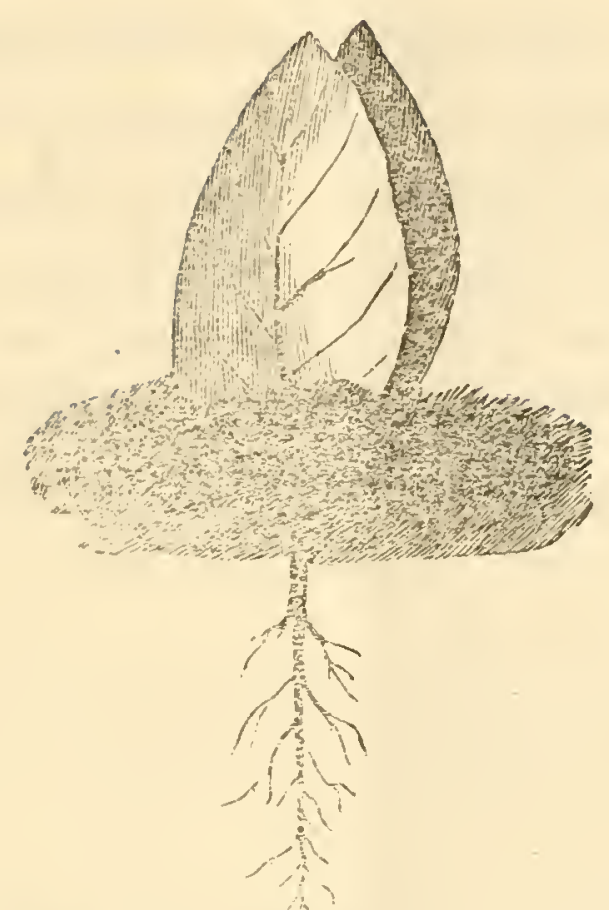

Fig. 2. Whe Plant and Poot as should be set.

are those which have leares abont three inches in length; but it is better to set much smaller plants, if the weather is favorable, than to wait for the plant to grow larger. A smail plant set early, will do better than a larger one set late. The plants when taken from the bed, should be placed carefully in a basket to be carried to the fiold; they are then dropped upon the hilis prepared for them, by a boy, who will precede the setters a few yards. Tran planting should be done on a rainy, or damp, misty day, to be most successful; this is always advisable when such days may occur, but if the time of setting is getting late, and the plants are large enough, setting may be done in dry weather by using water freely. It has been found best to water the grourd before putting in the plants, in this way: make a hole in the centre of the hill prepared for the plant, with the heel of the boot, and pour into it from a half pint to a pint of water ; let the water souk into the ground a little, and then 
set the plants. This process will require more labor, and is no better than the damp days. To make the dry weather setting more safe, the plants may be covered for a few days, with a little grass or green leaves, which should be taken off as soon as the plant has taken root and begins to grow. To set the plant, make a hole in the prepared hill with two fingers; fold the outer leaves of the plant together over the centre ones, or bud, then set it; care should be taken that the roots extend their whole length in to the hole, and the earth well pressed about them, and press lightly the loose earth about the base of the leaves to keep them in an erect position; this plan of setting, keeps the buds from the rays of the sun, and also secures more moisture about the roots. The first week in June, is the best time for setting in New York State; the time will not differ much, in any of the Middle States, and from this time till the 20 th of the month, or to the 25th, plants may be set; plants set later than this, will not be likely to attain so good a growth unless under very favorable circumstances; after the plants are set, it will be found necessary to go over the ground again, to fill up the vasancies that may occur; some of the plants may not live, and some may be destroyed by the grub worm, after they have taken root and begun to grow. A little experience will determine where the grub has been at work, and it may generally be found just below the surface of the ground, and near the plant, and should be killed. As a matter of convenience, it has been found best, when setting ont the plants, to set every tenth hill with two plants, say six inches apart, from which plants, vacancies can be sipplied during the first hoo. 
ing, which is considered a good time to fill up where plants have failed; the plant, if a large one, can then be set with a hoe, after having made a hole for it in its place, by using the hoe as a spade, and taking up earth with the plant, so as not to retard its growth. If the weather is favorable for re-setting, do not wait till the time of hoeing.

\section{HOW TO PREPARE THE LAND.}

If the land which is intended for a crop of tobacco, is sward land, it is better to put some other crop on it the season before it is wanted for this purpose, as sward land is not so good for tobacco, though a fair crop may be raised under favorable circumstances. The land should be well manured, and plowed in the month of May; with from twenty to thirty cords of good manure to the acre; for without manure, it is worse than useless to attempt to raise tobacco in the Northern and Middle States. The most common way of managing the manure, and plowing, is to spread the manure over the whole surface of the ground, and plow it under; but plow shallow the first time, say four inches deep; the second time, from seven to eight inches; thus keeping the manure under, and yet near the surface, where the young plants can get the benefit of it. Another plan which has proved very successful, is to plow and harrow in the fall, and then spread on the manure and let it remain till spring, then plow it in, harrow, and set the plants. After the land is well harrowed, mark it off as in planting corn, with a toothed marker, drawn by a 
horse; let the teeth of the marker be from three feet to three feet four inches apart, for the space between the rows; and if cross-marked, let the spaces be two feet apart, thus making the plants stand two by three feet, or three feet four inches apart. Two feet by three, is considered far enongh distant for the plants, but it is rather close for the cultivator, which is always used before hoeing the first time, and the second, if the plants are not too large, which is not generally the case. After marking oft the rows, small, shallow hills should be made with the hoe, for the purpose of having a well prepared spot, in which to set the plant. A little judgment must be exercised as to the heighth of the hills; if a part of the field is low, and liable to be wet during some parts of the season, it is well to make quite a hill, at least sufficient to keep off the standing water ; if the land is hilly, the hill will do withont any artificial hilling better than with it.

It is well to have the ground in readiness for setting a few days before the time of setting, so that there will be no delay when a good day ocenrs, which must be improved to the extent of the plants ready to set. Besides the advantage of having the hills ready in season to set when a damp day occur's, it has been found best to have the hills inale long enongh betrore the time of setting, to have them settleand become somewhat enmpact from rain, as a light, loose hill, not having been rained upon, may be too dry for the plants to grow, althongh the day may be favorable to set. To aroid any tronble on this hand, have the ground in readiness for a weck before it may be wanted to set the planis out.

The object in having the rows as near together as 
can be well cultivated, and the plants as near as they can grow, and yet attain a good slificient size, is mainly to insure a light, thin leaf. If plants are set at greater distances apart, so that each plant will be a separate one, that is not influenced in its growth by contact with other plants, and if a large growth is attained, the leaves will be thicker, the veins larger, the texture will be coarse and spongy, and the color less likely to sweat evenly.

\section{HOEING AND WEEDING.}

The hoeing should be commenced as soon after setting, as the weeds begin to grow, and they should all be kept out of the field. The ordinary method c f weeding corn, is the same as practiced in weeding tobacco. At the second hoeing, small or shallow hilling, may be advantageous, to prevent standing water about the roots of the plants. Much hilling will interfere with the leaves. If the land is very weedy, a third hoeing will be necessary. After, or during the second hoeing it will be well to look after the tobacco worm, which mnst be taken from the plant and killed, or the worm will destroy the tobacco. The first appearance of the worms can be determined by small round holes in the leaf; at their first beginning to eat the leaf, they are abont half an inch in length, their growth is rapid, and at full size they are about three inches in length; to find them, turn up the leaf and look for them on the under side; if not found on the eaten leaf, they can generally be found on some leaf of the plant. They are much casier found when small than afterward. 


\section{TOPPING.}

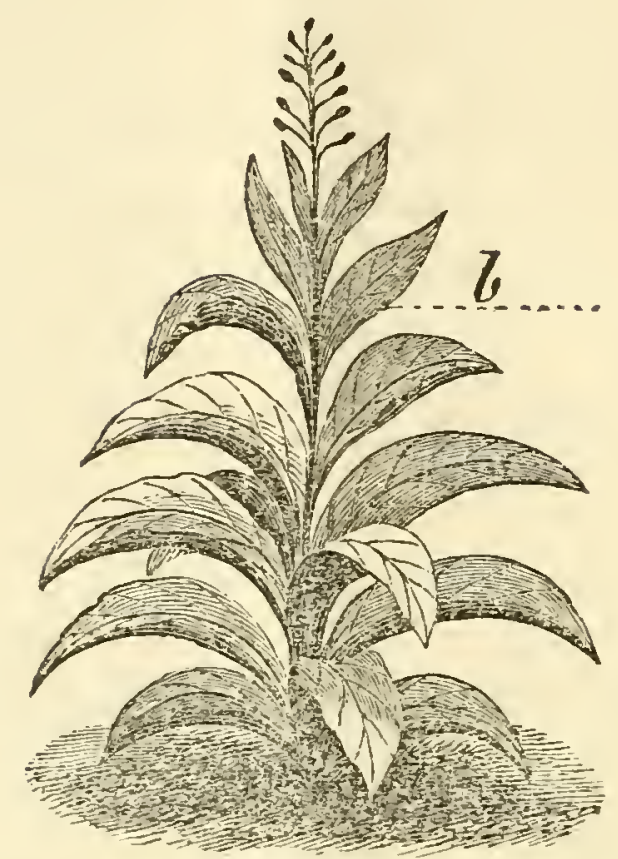

Fig. 3. A Plant ready to Top. Place for Topping indicated by b.

Topping consists in breaking off the top of the plant, after it has grown so as to show the buds fully, arid before the flowering; figure ( 3 ) represents a plant ready for topping, and the horizontal line, the point at which the top should be broken off. What is called low topping is considered advantageous to the growth of the leaves remaining. In low topping four leaves are included with the bud stalk, which is taken

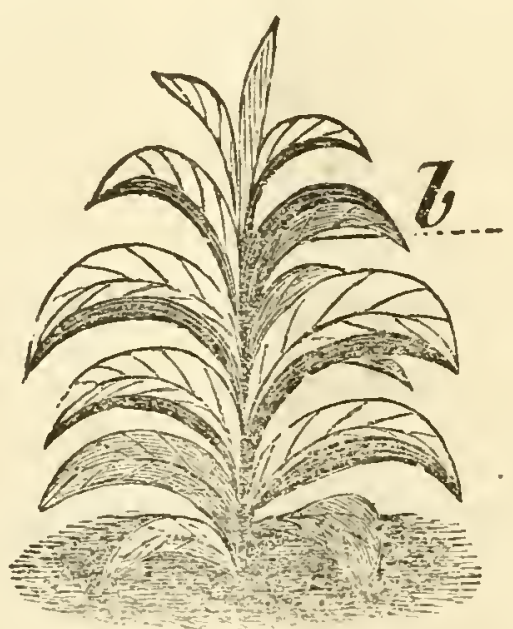

Fig. 4. A small Plant to be Topped in the season and at the same time of Topping as in Fig. 3. 
off from the plant. When the largest part of a field of tobacco is ready to top, it is best to top all the plants that have not attained full size; if any are quite small as in fig. (4) cut out the bud, if it is necessary to open the leaves to find it, as there will be no advantage in waiting for the backward plants to come forward to the state necessary to topping in an earlier part of the season, but on the contrary, if the backward plants are left to gain full size before topping they will be found to be infericr in all respects, and will not be ready to harvest when the other plants are.

Top low and thoroughly, commencing on that part of the field where the setting commenced, the first set plants will generally be more forward than those set later.

It is difficult to give dates or the days of the month, in the management of a growing crop of tobacco, as a few days, will make quite a difference in the appearance of a crop.

The time of setting we have given, and the time of harvesting will be found under that head.

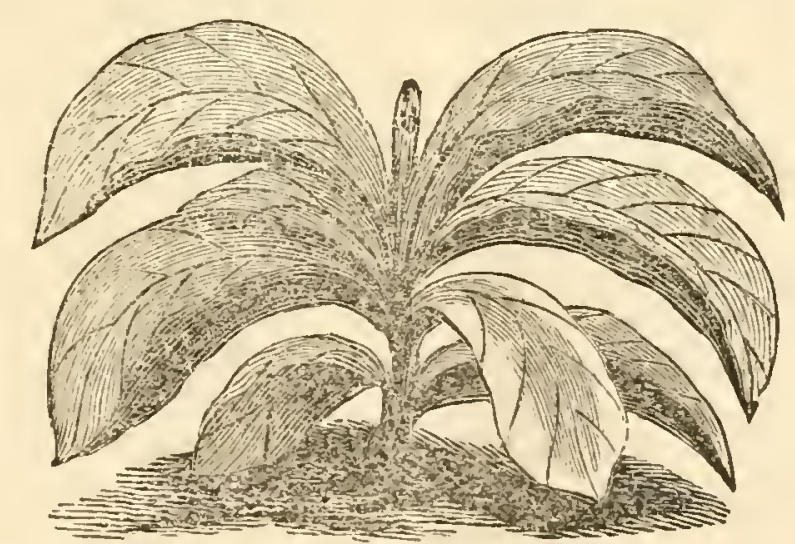

Fig. 5. Plant after Topping.

After topping, say from six to eight days, the tobacco must have all the suckers or shoots broken off, 
that will grow ont between the leaf stalk, and the main stalk; these shoots or suckers will, if not taken off, retard the growth of the leaf, and injure it while curing on the stalk; they will continue to grow when in the tobacco house, and keep green for a long time and rot the leaves that come in contact with them' when stacked for stripping.

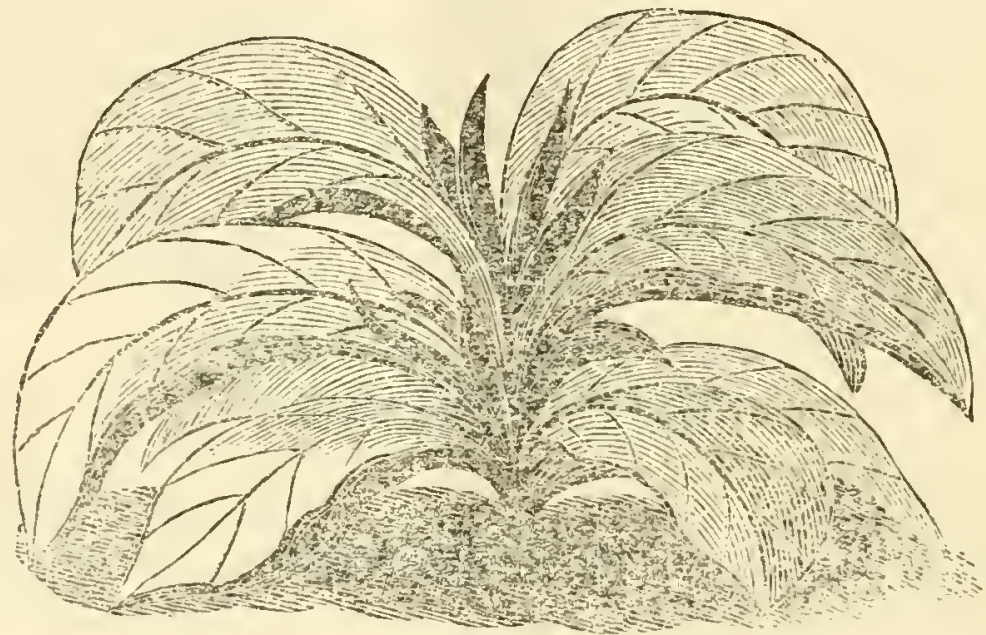

Wig. 6. Plant with Suckers growing.

\section{HARVESTING.}

The time for harresting must depend somewhat on the state of the crop, thongh it should never be left in the field till too ripe, as a thick hard leaf will be the resuit. Nor should it be left so long that it may be liable to get an early frost upon it, as frost kills the tobacco and renders the crop worthless; as a general rule, the time for harvesting, is the first week in September ; in the absence of any experience, cut the tobacco the first week in September,-say from six to ten days after topping.

The manner of harvesting, is as follow: Cut the plant with a hatchet, between the lower leaves and the ground; in order to do so, take hold of the stalk 
of the plant by the left hand, and press it over, so as to come at the work handily. After it is cut, lay it down on the left hand side gently, so as not to break the leaves from the stalk, with the butt of the stalk towards you, for convenience in handling. Cut the tobacco either in the morning, or late in the afternoon; that cut in the morning, should lay on the ground long enough to wilt the leaves, so that the plant can be handled without breaking; after it is so wilted, it can be gathered. That cut in the latter part of the afternoon, may lie on the ground over night, and be gathered the next forenoon. The object in cutting in the morning and evening, is that the tobacco may be got into the tobacco house before noon, and this is only necessary when the sun is out, and scorching hot. Should the day be very warm with a hot sun, the tobacco that is cut, should be gathered up and housed, in the early part of the day, as the effect of a hot sun on the plant is equally injurious as frest; it will burn the leaf and destroy it. In cool weather, this precaution is, of course, unnecessary. When there is a heavy dew on the plants, if left to dry off partially before cutting, they will wilt sooner, and will not require turning over, which is sometimes necessary. If by accident, there shculd be danger of getting the tobacco burnt by the sun, in the absence of the cart for removing it, it can be piled up in heaps, till the means of removing is at hand. A wagon without side or end boards, is preferred for carting from the field to the tobacco house; place the plants on the wagon with the butts all on one side, and as straight as convenient, in order that they may be taken off without tearing the leaves; which is a mat- 
ter to be looked after, during the whole process of raising and curing tobacco.

\section{PIAN OF TOBACCO HOUSE.}

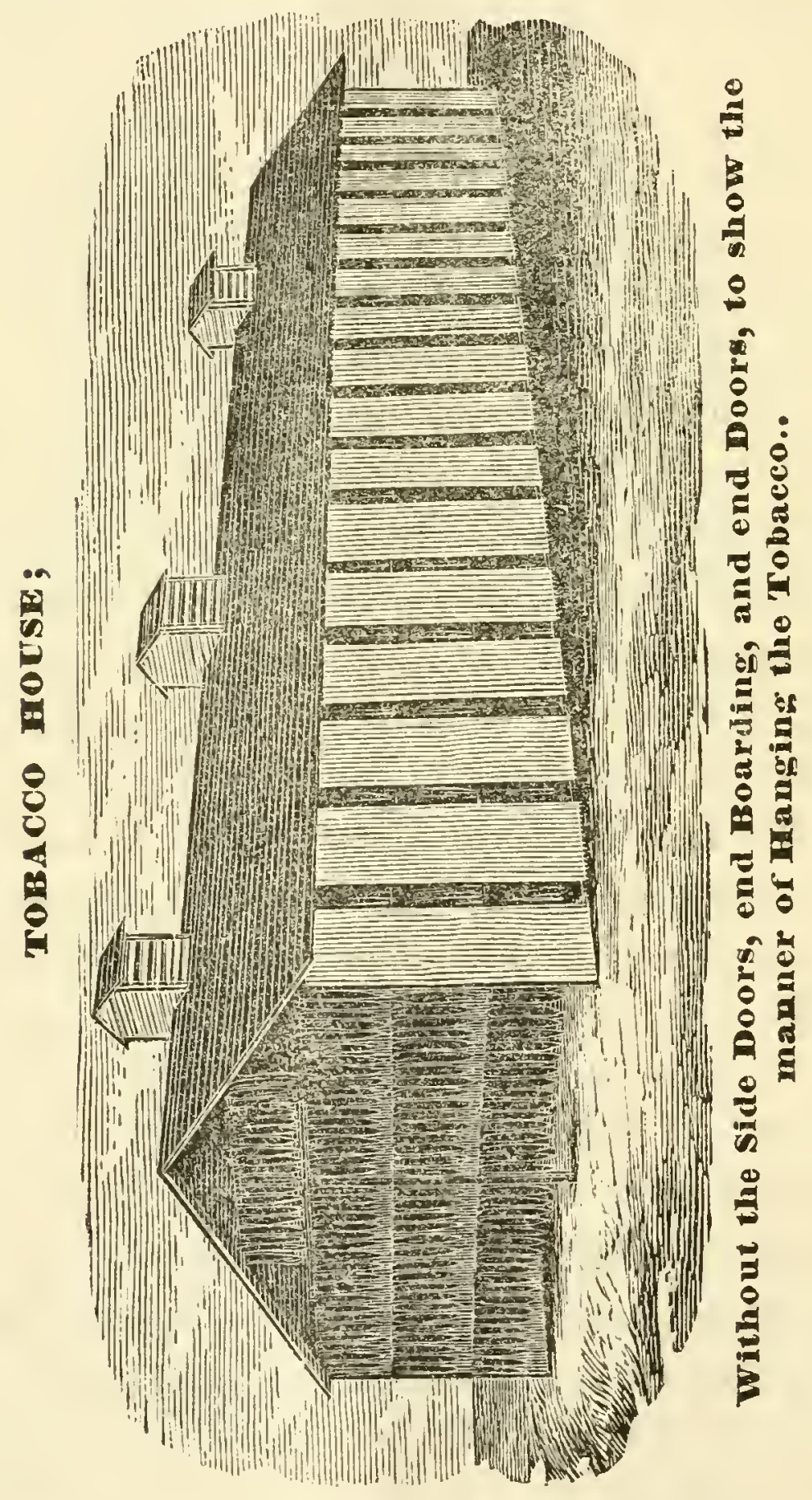

When tobacco raising is to be followed to any considerable extent, a :Tobacco House should be built 
expressly for the purpose of hanging, stripping, curing and boxing. The size of the building is to be determined, by the number of acres to be raised. The manner of building generally practised is as follows: Take for example, a building twenty-four feet by one hundred feet, with a twelve feet stud, which is of sufficient capacity to hang, say four acres of tobacco. This wil! give three tiers of polls, four feet apart, besides what may be hung in the attic. The framing of the building should be so arranged, that in a building twenty-four feet wide, posts should run through the centre of the building, say twelve feet apart, with ties between each, of sufficient strength to hold the poles and the tobacco. These centre ties or girts have corresponding ones on the sides of the building, and are placed four feet apart, to allow of sufficient space for the tobacco bung on the polls. Two girts only will be necessary between each post, as the plates, and the beams in the centre will take the place of a third girt. There should be large double doors at each end of the building sufficiently wide for a loaded wagon to enter for unloading. It is well to have two ventilators on the tup of the building one hundred feet long. Vertical boarding is preferred, as at every four or five feet there should be one board hung upon hinges to be used as doors, these doors are to be opened in dry weather, and closed, on damp, windy, and rainy dars. If the doors are left open, when the wind is high, the tobacco will become badly broken, and torn from the poles; and on the other hand if the building is not opened so as to have a good circulation of air among the tobacco, it will become pole burned, as it is called; this state will be indicated in the first 
instance, by the tips of the leaves turning white, or a pale yellow, and they will be soft and slimy, and after curing, they will become black and brittle, and destroyed for wrappers.

\section{HANGING.}

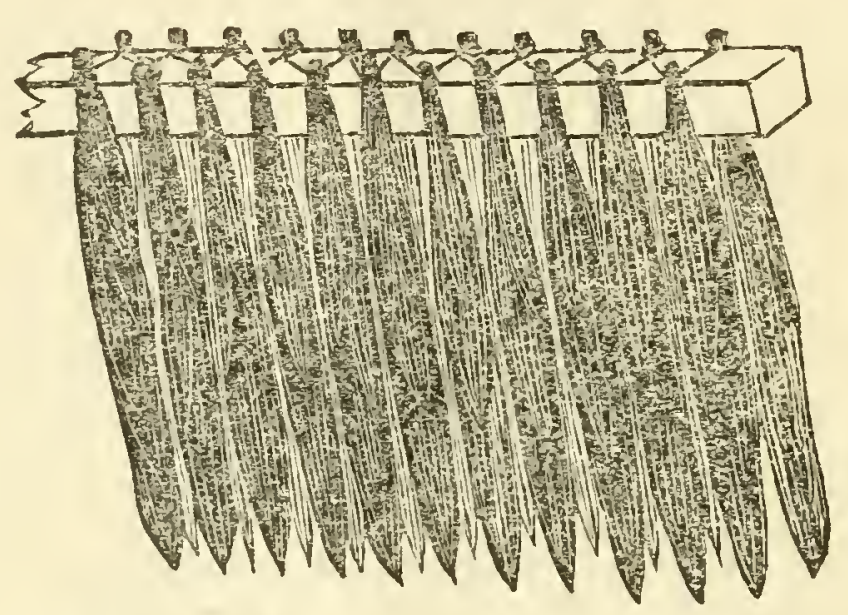

Fig. 8. Fobbacco on the Poles.

Any kind of poles will answer to hang the tobacco on that is strong enough. When there is a tough. light timber to be had easily, sawed strips four by two and a half inches, twelve feet long, will be found most convenient for handling, and tying up the tobacco. In hanging the tobacco, commence at the top of the building and work down on one side first; by this means one half of the building, which has large doors to admit of a team going through, can be used for a passage way, for the convenience of unloading.

In hanging the tobacco, one person should take the plants from the load, and toss them butt first to another person on the poles, who will hand it to the one engaged in hanging.

This is the most convenient method, and also the best, as the tobacco will get less torn in this way than 
when fewer hands are emplojed, and the tobacco is thrown up on to the poles in heaps. During the hanging of the crop, there will be a great many loose and broken leaves about the house; it may pay to tie these up in small bundles and hang them up to dry, as they will answer for fillers. The manner of securing the tobacco to the poles, or hanging, as it is generally called, is as near as may be described, as follows:

A man standing on a plank, or the poles of the tier below where he is to hang the tobacco, takes the tobacco in his left hand, and after tying a stong twine, (in balls) to the butt of the first plant, places the second, on the opposite side of the pole, and secures it by making a turn of the twine around the butt of the plant and over the stalk of the lower leaves, and continues to place the plants in this way, on opposite sides of the pole, about six inches apart; when the plants are small they can be placed nearer. The plants should not be opposite each other, (see fig. 8.) This process is continued to the end of the pole; the string may then be continued to the next pole, and the first plant secured by passing the twine round it as be fore. Pass the twine in front or beyond the stalk of the plant, round on the outside, and cross over the pole to the opposite plant. A strong cotton or flax twine, that will be soft to the hand will be preferred. Let the poles be about one foot apart, after the tobacco is hung, if it is full grown; and they may be nearer, if the tobacco is small. After the tobacco is secured on the poles, nothing more is to be done until it is sufficiently cured to take down for stripping; except to open, and close the side doors, as the weather may require. 


\section{TAKING DOWN.}

The method of taking down tobacco from the poles, as generally performed, is to gather an arm-full, and cut the string, by drawing a knife over it on the top of the pole, which, if a sawedone, is quickly done. A little enconomy may be practised by unwinding the twine with one hand, and gathering the tobacco with the other, thus saving the twine; lay the tobacco on the poles as fast as gathered, or hand it to some one, who will stack it up for stripping. In stacking it, make two tiers, with the butts on the outside, and the tips to pass over half the length of the stalk and leaf ; this stacking is necessary to keep the tobacco moist, so that it can be handled without breaking, and it may be kept in this way till the stripping is done. It is necessary to cover the tobacco after stacking, with mats, old carpeting, or boards to kecp the tobacco moist. Tobacco taken down for stripping, and packed to keep moist, is liable to heat in the stack, if quite damp when taken down, or if it remains too long in the stack. The stacks should be examined, and if a sweat is indicated they should be opened and aired and repacked lightly-if there is more in the stacks than can be readily stripped.

The quantity to be taken from the poles at one time, will depend on the number of hands engaged, in stripping and sorting.

When tobacco is taken from the poles to strip, before the main stalk is dried out, that is, while it is still green, it should not be packed away to remain, but should be stripped within a day or two after it is taken from the poles, as the green butts will rot the leaves 
when pressed closely to them in the stack. If the stacks are well cured and the leaves are not very damp it may remain in the stack two or three Nays longer.

\section{ASSORTING AND STRIPPING.}

Assorting and stripping should be done, if the weather is cold, in a tight and well lighted building; it is well in constructing a tobacco house to part off some twenty feet by twelve, for a stripping house, so arranged that a stove can be put up, and the place heated; the work will be done much better in a warm and comfortable room.

When the tobacco is ready for stripping, may be determined by examining the leaves to see when they are cured. If the stem of the leaf is cured out, or so dry in dry weather, that it will break at the butt, or near the foot stalk, it may be considered sufficiently cured to take down from the poles for stripping. Tobacco in New York State, in the central counties, does not generally get cured and ready for stripping, till the first of December. In Connecticut it is ready for stripping some four weeks earlier, and varies in this respect in different localities, according to the climate; not so much with reference to heat and cold as such, as to the dryness or dampness of the atmosphere. There are fewer clear, dry days in the month, in central New York, than in Comnecticut; consequently, tobacco does not cure on the poles in these counties, in as short a time after housing, as in Connecticut. Stripping and boxing is done in Connecti- 
cut in the fail and early part of the winter, while it cannot generally be done in Western New York, till winter, or early spring. When tobacco is boxed in the fall, less atmospheric moisture will be required than when boxed in the spring; as, after a wiuter curing, there will be less moisture in the stem and leaf, and less danger of getting the tobacco too damp for the box.

Assorting and stripping are done at the same time. The method usually practiced, in assorting and stripping is as follows: Hold the stalk of tobacco in the left hand about mid way, so as to balance it, and not fatigue the hand. If three grades are wanted, gather the poorest or third quality in the right hand, drop the second on the floor, and leave the first on the stalk to be taken off by a stripper, and made into a "hand," or lay it down till the assorter gets ready to strip it himself. If there should be, as there sometimes is, what are called fat leaves, cr leaves on the upper part of the stalks, that are not dried out and eured, but were frozen before getting cured, do not throw them away, as they are worth saving; hang them up by their tips and liang them astride the poles to dry. A little experience is necessary to sort well, as the quality of the leaf is to be determined qaickly by the eye, when holding up the stalk, and sometimes by passing the hand over the leaves, the better to determine their texture or soundness. The lower leares are the poorest, and when three grades are wanted, are, with badly torn leaves, put with the third grade. The top leaves, when small or narrow, and good leaves, one half of which are torn, together with light colored leaves, (that may have become somewhat dried before 
cutting, and may not, during the sweating process take a good color,) are put with the second quality. For the first grade or Number ('ne, none but the very best leaves should be.taken. Too little care has been taken in assorting heretofore among many growers, and as a consequence, they get a less price for their oun crop, and render buyers suspicicus of all crops. Many buyers of Seed Leaf Tobacco, as the Ohio, Pennsylvania, New York and Connecticut tobacco is called, from having been produced from the seed of the Havana tobacco, do not consider it of sufficient consequence to warrant the extra trouble in making more than two qualities; in this case the second and third qualities are put together.

It is very important to have tobacco well assorted as, on this, trigether with the sweating, if previously well managed, depends its value in the market. The difference in the value of a crop of tobacco properly assorted and sweat, and one carelessly, or ignorantly managed in this respect, may amount to more than onc half the whole value of the crop. This diffirence may easily be saved, by a little care, and such knowledge as may be obtained. Put none but the best leaves, the largest, broadest, the most sound or least torn, and best colored leaves into the first qual. ity ; avoiding narrow thick leaves at the top of the stalk, which there will be unless the tobacco is topped low. The luw topping as was remarked in a former chapter, will increase the value of the crop more than the loss of the leaves broken off", and thrown away with the seed buds.

When tobacco is assorted and stripped, it is made into hands, as the parcels of tobacco are generally 
called; which are small h ndfulls of leaves buund about the butts with a leaf, in such a manner as to hold them together. A box for each cuality to put the tobacco in while stripping, is a convenient arrangement. After a day's stripping pack the hands away in a stack, with the butts.ont, and the tips to lap over each other, equal to half the length of the hands. The object of packing the tobacco away at this stage is, that the butts of the leaves may becone more thoroughly cured, and also to keep the leaf in a soft, pliable state, till a sufficient quantity is stripped, to allow of boxing.

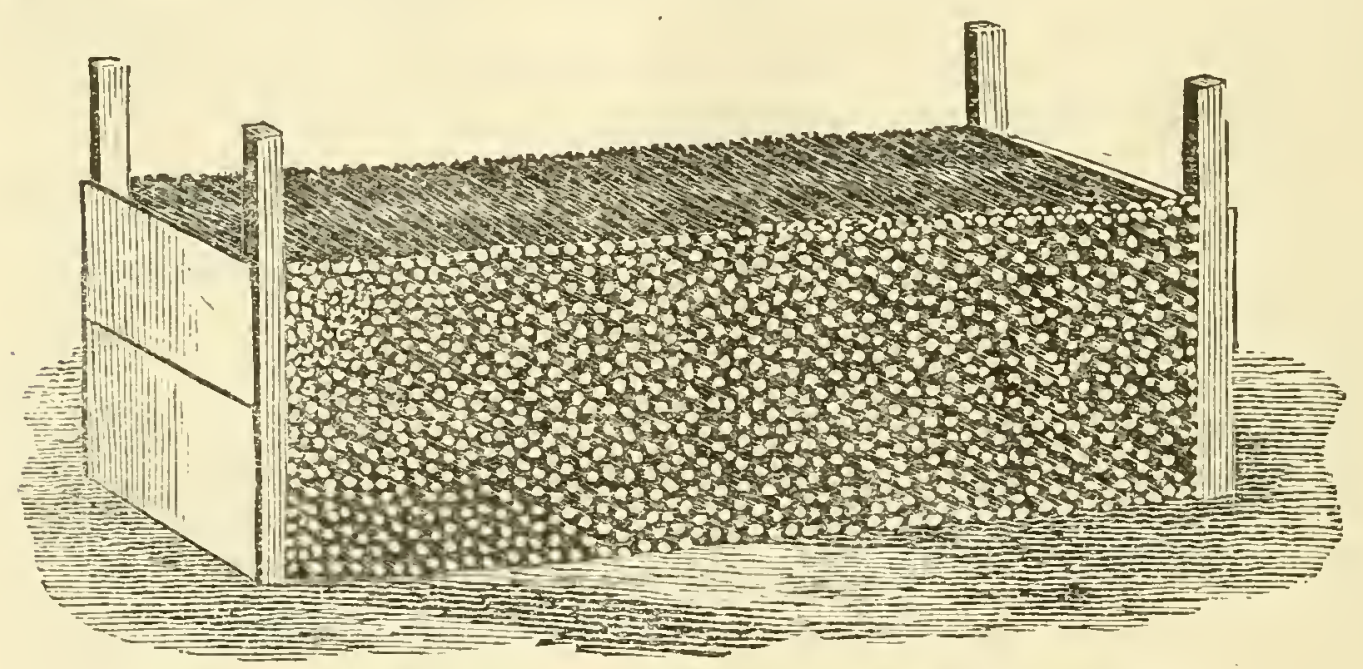

Fig. 9. Tobacco Stuclod after Stripping.

It is well in packing awsy, to make as square and compact a stack as presible, with the buits only exposed to the air, keeping the top and ends, but not the sides of the stack covered with boards or matting; if with boards, pat just weight enough on the board to press the whole, so the at all may be covered. This covering is to keep the tobacco moist and soft, for if it becomes very dry, it is difficult to get it damp enongh when it may be wanted for boxing, which can be done at any time after packing, when in a proper state. It is best to manage a crop of tobaceo when 
taken from the poles, without the use of water to moisten the leaves, depending entirely on the action of the atmosphere, to produce that state of dampness which will enable one to handle the tobacco without bres.king. In no stage of proceedings should the to. bacco be handled, rnless it can be done without breaking the leaf. If the tobaceo is hard and dry, wait till it is soft and pliable, and there will be no difticulty in the case, if the handling is done at as early a day, as it can be done. When satisfied that the tobacco is sufficiently, cured to take down from the poles, take advantage of the first wet weather, when the leaves will be soft. Continue to take advantage of the weather, until the whole is taken down, stripped, stacked, boxed, and ready for the market.

\section{BOXING.}

The size of the boxes generally used, is two fest four inches by three feet six inches, and made of soft wood; pine is preferred, and should be seasoned. In making the boxes, secure a strip of board into the comers, to nail the ends to, say two inches by one inch, or one and a half inches square. "To determine when the tobacco is ready to put into the box, is perlaps the point requiring the mast judgment and experience. As on the state it is in when boxed, will depend the character of the sweat, and on the sweat the value of the tubacco. The only rule that can be given in the case is this:

The tobaceo should be perfectly soft and pliablo, without being wet or sticky, or greasy, as it is called; 
and as a general rule there will be no difficulty in having the tobacco in this state, if only the atmosphere is depended upon for moisture, aud the leaf well cured before taking it from the poles. In putting the tobacco in the box, should there be some of the hands a little more moist than other's, put these hands on the top, bottom, and sides of the box. If some of the hands are too dry, they cannot be put in the box until they become soft, and must be covered up, till a damp day occurs. If some of the hands are too moist, they call be dried a little while boxing, or put with hands too dry, to moisten them, when both can be boxed.

If Tubacco is in a wet, slimy state or in other words, too damp, when plit into the box, it will sweat too m!nch, and become tender; which lessens its value materially. Care should be taken to have the 'Tubacco just right, when it is boxed; and this state has been described as nearly as it could be. A more complete understanding on this point must be gained by experience.

If the weather is favorable for moistening, and the tobacco requires it before boxing, uncover the stack, that a unitorm dampness may be produced. In boxing, lay the hands of the tobacco lengthwise of the box, the butts to the end of the case; lay the leaves and hands all straight, and fill up the case to the top, without getting into the case on hands and knees, as the fashion of some is; then place a follower the size of the inside of the box on the tobacco, to allow of its being pressed; the fullower is made of two inch plank, with cross cleats on the top to prevent sulitting, and on which blocks are to be laid in pressing. A lever press, consisting of a long and stout pole is gen- 
erally used. Place the box under a beam, in the stripping-house, and secure with a rope, or a chain, a piece of scantling to the beam, to be used as a fulcrum to the lever. After having pressed the first quantity in the box, remove the follower and commence putting into the box a second time, and then press again, and so on, until the box is full. From 350 to 400 pounds is considered sufficient to put into a case; a much smaller quantity will not sweat well. If convenient, two positions for placing the boxes may be had, so that one can be filling, while the lever is left on the other, to preserve the pressure gained.

A screw press has been made for pressing Tobac. co, that is more convenient than a lever, and does not cost much. It can be made for about six dollars.

It is made as follows: Take for the bottom of the press, a piece of plank 3 inches thick, 2 feet wide and 3 feet six inches long; into this bottom piece are set two side pieces of plank, 2 inches thick, 8 inches wide at top, 16 inches wide at the bottom, and 3 feet 8 inches long; the side pieces are secured at the top by a cress bar, through which the screw is to pass; the top bar, to be 3 inches thick, 8 inches wide, and 3 teet 6 inches long. Space between the sills to be 2 feet 8 inches, to admit of the box. The side pieces to be morticed into the top and bottom; an iron rod is set in a groove, cut in the side pieces, and secured at the bottom of the press by a bolt head, and at the top by a screw and nut; rods to be $3-4$ inch round iron. These rods are necessary to hold the press together. The screw is 18 inches long by 2 inches in diameter, made of cast iron, with a large head, and a hole in it, to put a lever through. On the under side of the top bar is an 
iron plate with a thread to correspond with the screw. The plate is secured to the bar. Making a portable and convenient press, which can be used für many purposes.

After a sufficient quantity is put into the box, remove it from the press, put the cover on the box, and nail it securely. The boxes should then be placed in a dry, close building, and may be packed one case upon the other, and left till the sweat is over, which will cummence in a few days after boxing, if damp when packed, and the weather u ild.

The sweating process is completed during the spring and summer, and the tobacco is generally fit for use, one year after gathering, though it would be preferred the spring and summer following. When the tobacco is in full sweat, the cases may be warm, which is a good indication-and they must not be opened. They may be turned over, in order that the tobacco may be uniformly sweated, or at least those cases that may hare their sides exposed to the air.

\section{COLOR.}

The color that tobacco will take in sweating, will depend somewhat on the col $r$ it has acquired in curing on the poles, as also on the state it is in when boxed. If tobacco is too dry when put into the box, it will sweat but little, and the colors will remain unchanged. If in a proper state, as advised, the sweat will be sufficient, and will produce a uniform and desirable brown. If the tobacco is quite damp, a little 
more so than is absolutely necessary to sweat well, it will have a very dark blown color. The dark brown colors are most desirable in the market at the present time. The particular shade of a tobacco leaf, is a matter of fashion, as much so, perhaps, as that of any other article in the market. 




\section{LIBRARY OF CONGRESS

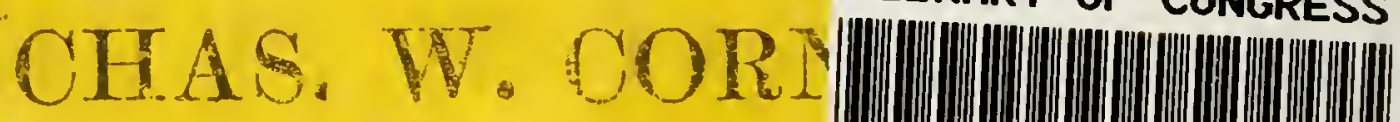 Wholesale AYI TETAL DEALER 00014550331}

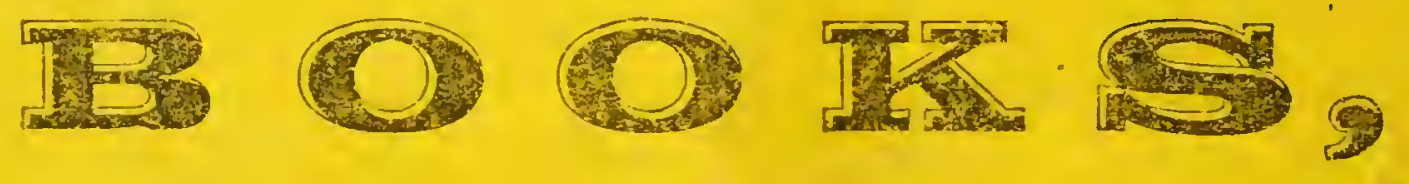

PHOTOGRAPHIC ALBUMS,

BIAIII BODIE,

STATIONERT, and

FATCYOCONS.

TIE LIRGEST ASSORTHENT OR

PAPER HANGINGS

IN CENTRAL NTW YORK.

[CF Wholesale Lealers supplici at Lowest New Iork Prices. CHAS, W. CORNELL,

No. 19 S. Salina, St., Syracuse, N. Y. 